\title{
Administração pública e terceiro setor
}

Magno Federici GOMES ${ }^{1}$

Daniela Duarte PORTES ${ }^{2}$

\begin{abstract}
${ }^{1}$ Pós-doutor em Direito Público e Educação pela Universidade Nova de Lisboa-Portugal. Pós-doutor em Direito Civil e Processual Civil, Doutor em Direito e Mestre em Direito Processual, pela Universidad de Deusto-Espanha. Mestre em Educação pela PUC Minas. Coordenador do curso de Direito da Faculdade Padre Arnaldo Janssen. Professor do Mestrado Acadêmico em Direito do Centro Universitário UNA. Professor Adjunto da PUC Minas. Advogado Sócio do Escritório Raffaele \& Federici Advocacia Associada. E-mail: federici@pucminas.br

${ }^{2}$ Graduada em Direito pela PUC/MINAS. Pós graduada em Direito Civil e metodologia do ensino superior pela PUC MINAS. Mestranda em Gestão social, educação e desenvolvimento local pela UNA. Professora do curso de Direito, do MBA de Auditoria e gestão da qualidade do serviço de saúde e da Pós Graduação em Direito Público do Centro Universitário UNA. Professora da Pós Graduação em Poder Judiciário do Instituto de educação continuada IEC/PUCMINAS. Coordenadora do curso de Direito da Faculdade UNA de Contagem e Coordenadora do curso de Direito e da Pós graduação em Direito Público do Centro Universitário UNA.
\end{abstract}

Recebido em: 09/10/2012 - Aprovado em: 20/12/2012 - Disponibilizado em: 30/12/2012

\section{RESUMO:}

O terceiro setor existe no contexto brasileiro desde sua colonização, mesmo que apresentado outras características como organizacional e legislativa, as ações sociais e preocupações de pequenos grupos e igrejas sempre foram atuantes no contexto social. Com o passar do tempo e até mesmo como ferramenta para auxilio da administração pública o terceiro setor começou a ser reconhecido e regulamentado. O artigo aqui apresentado demonstra através de uma análise empírica em artigos científicos coletado na base de dados da Scielo, os principais aspecto que compõe a participação do terceiro setor, mais especificamente as OSCIP's , tanto na figura de parceiro do Estado quanto em sua atuação dentro do atual cenário.

Palavras-chave: ONG, terceiro setor, OSCIP, parceiros da administração pública

\section{ABSTRACT:}

\section{Public administration and third sector}

The third sector exists in the Brazilian context since its colonization, even though other characteristics presented as organizational and legislative actions and concerns of small social groups and churches have always been active in social context. With the passage of time and even as a tool to help public administration the third sector began to be recognized and regulated. The article presented here demonstrates through an empirical analysis of journal articles collected in the database of scielo, the main aspect that makes up the involvement of third sector, more specifically the OSCIP's, both in figure partner of the state and in its role within the current scenario.

Keywords: ONG. Third sector. OSCIP. Partners of Public Administration.

\section{INTRODUÇÃO}

O terceiro setor pode ser apresentado como um conjunto de atividades sociais que não está sob a administração do estado. No Brasil esse setor tem características e desenvolvimento histórico ao se considerar desde a colonização os serviços prestados pela igreja onde a partir de então passou a se manifestar e aprimorar sob diferentes óticas e objetivos, sendo utilizado após a década de 30 como ferramenta estratégica do governo, sendo regulamentado então o terceiro setor a partir da década de 70 onde esse passa então a possuir características filantrópica, assistencialista e social, sendo efetivado então 
na Constituição de $1988^{1}$, porém, mesmo com essa aceitação apenas a partir da década de 90 que o terceiro setor foi considerado como participante ativo da economia. ${ }^{2}$

A importância do terceiro setor foi se consagrando e sua evidencia ficou clara na sociedade moderna ou ser considerado, ao lado do Estado e do Setor privado , os três pilares que sustentam a sociedade.

Menezes $^{3}$ denomina o interesse do estado no terceiro setor como sendo uma união de parceria administrativa e consequentemente as empresas se encaixariam nesta "parceria" dento do processo societário organizacional e administrativo. Já caracterizado por Silva ${ }^{4}$ ao mensurar o terceiro setor dentro da égide dos setores, sendo o primeiro setor o Estado o segundo as empresas e industriais e o terceiro setor as ONGs etc.

Dentro deste contexto o presente artigo será apresentado com aval literário a importância do terceiro setor bem como a importante parceria entre os setores e a defesa desta, principalmente das OSCIP's como importante ferramenta para o Estado na execução e efetividade em seu processo.

\section{DESENVOLVIMENTO}

Carrion $^{5}$ apresentou em seus estudos a participação das empresas privadas no terceiro setor, concluindo suas respectivas participações como sendo fundamental para o

1 CARRION, Rosinha Machado. Organizações privadas sem fins lucrativos: a participação do mercado no terceiro setor. Tempo soc. [online], 2000, v. 12, n. 2, p. $237-255$.

${ }^{2}$ MADEIRA, Felícia Reicher; BIANCARDI, Miriam Ribeiro. O desafio das estatísticas do Terceiro Setor. Perspec. [online], 2003, v. 17, n. 3 - 4, p. 177 - 184.

${ }^{3}$ MENEZES, Franciane Cristina de. O Serviço Social e a "responsabilidade social das empresas": o debate da categoria profissional na Revista Serviço Social \& Sociedade e nos CBAS. Serv. Soc. Soc. [online], 2010, n. 103 , p. $503-531$.

${ }^{4}$ SILVA, Carlos Eduardo Guerra. Gestão, legislação e fontes de recursos no terceiro setor brasileiro: uma perspectiva histórica. Rev. Adm. Pública [online], 2010, v. 44, n. 6, p. $1301-1325$.

5 CARRION, Rosinha Machado. Organizações privadas sem fins lucrativos - ob. cit., 2000, p. 237 255. crescimento social do Brasil, bem como essencial dentro do processo de conscientização e responsabilidade sustentável das empresas.

Lopes $^{6}$ enseja o terceiro setor na administração publica como estando dentro e subjulgada a esfera da gestão social, porém, esta não tão fácil de ser especificada ou conceituada devido às relevantes e variantes aspectos e circunstâncias que nela estão envolvidos. ${ }^{7,8}$

De acordo com Menezes:

$$
\begin{aligned}
& \text { O discurso de "crise do } \\
& \text { Estado" e de sua ineficiência } \\
& \text { de gestão se fortalece ao } \\
& \text { mesmo tempo em que é } \\
& \text { repassada para a sociedade, } \\
& \text { via solidariedade e filantropia, } \\
& \text { a responsabilidade pelo } \\
& \text { atendimento das demandas } \\
& \text { sociais resultantes da "questão } \\
& \text { social". }
\end{aligned}
$$

Assumpção e Campos $^{9}$ avaliam que dentro do contexto do terceiro setor e das ONG's são necessários diversos entendimentos quanto a sua formação, defendendo então o modelo de avaliação das ONG,s, apresentando-as da seguinte forma:

(...) cinco grupos de ONGs:
históricas, novos movimentos,
prestação de serviços,
fundações e institutos e
filantrópicas.... Assim, um
primeiro cenário que emerge
ao analisar os processos
avaliativos e os focos de
atuação de tais ONGs se
caracteriza pela existência de
uma tendência de que as

${ }^{6}$ LOPES, José Rogério. Terceiro setor: a organização das políticas sociais e a nova esfera pública. Perspec. [online], 2004, v. 18, n. 3, p. 57 - 66.

${ }^{7}$ MADEIRA, Felícia Reicher; BIANCARDI, Miriam Ribeiro. O desafio das estatísticas do Terceiro Setor ob. cit., 2003, p. 177 - 184.

${ }^{8}$ MENEZES, Franciane Cristina de. O Serviço Social e a "responsabilidade social das empresas" - ob. cit., 2010, p. 503 - 531.

9 ASSUMPCAO, Jairo José; CAMPOS, Lucila Maria de Souza. Avaliação de projetos sociais em ONGs da Grande Florianópolis: um estudo sobre modelos relacionados ao foco de atuação. Rev. Adm. Pública [online], 2011, v. 45, n. 1, p. 209 - 242. 


\begin{abstract}
organizações que atuam apoiadas pela cooperação privada, pelo Estado ou organismos internacionais, e cujos focos de atuação expressem valores técnicos como profissionalização, saúde, educação e gestão, tendem a utilizar modelos centrados em objetivos e administração, em função das necessidades de se estabelecerem indicadores sólidos de eficiência e eficácia da intervenção social.
\end{abstract}

Assim, nesse reconhecimento e na preocupação de regulamentação do setor como parceiros do estado surgem as OSCIP's o Voluntariado que segundo Silva: ${ }^{10}$

A legislação também sofreu modificações, incluindo a promulgação das leis do Voluntariado e das Oscips e a reformulação do Código Civil. Em nenhum período a gestão das organizações foi posta tão em foco. Todas as práticas de gestão até então desenvolvidas foram reforçadas e novas práticas foram introduzidas, como o marketing especializado, a gestão de voluntários e as auditorias externas. Ainda observou-se a formação de profissionais especialistas em "terceiro setor".

Dentro deste contexto pode ser considerado então que desde o governo de Fernando Henrique foi constatado o inicio da parceria ativa entre o Estado e o terceiro setor, especialmente na regulamentação deles, bem como o reconhecimento e importância das OSCIP's.

Peci et al ${ }^{11}$ rememoram que:

\footnotetext{
${ }^{10}$ SILVA, Carlos Eduardo Guerra. Gestão, legislação e fontes de recursos no terceiro setor brasileiro - ob. cit., 2010, p. $1301-1325$.

${ }^{11}$ PECI, Alketa et al. Oscips e termos de parceria com a sociedade civil: um olhar sobre o modelo de gestão por resultados do governo de Minas Gerais. Rev. Adm. Pública [online], 2008, v. 42, n. 6, p. 1137 - 1162.
}

Os novos instrumentos jurídicos acima mencionados foram responsáveis por viabilizar a estratégia de cooperação do governo com o terceiro setor e o setor privado, ao longo dos últimos anos. No entanto, eles também tornaram mais complexos os arranjos institucionais utilizados para essa finalidade, uma vez que multiplicaram os atores e as formas de relação entre eles.

Essa legalização e facilitação pode ser observada a partir da lei Lei n. 8.666/93, Lei n.9.790/99 que facilitou os recursos recebidos por estas instituições, fazendo assim com que a viabilidade de muitos projetos por estas apresentados fossem efetivados de maneira mais rápida e efetiva.

De acordo com Peci et al..$^{12}$ um dos grandes entraves para a melhor parceria entre o Estado e as OSCIP's são as burocracias fiscais existentes nos processos para viabilização de projetos e parcerias, mesmo que se entenda que: "No que se refere à relação entre o Estado e as Oscips, vale salientar que o primeiro "não deixa de ser o responsável pelo serviço perante a população".

Concluindo este capítulo observa-se:

A contratualização é o
principal instrumento
gerencial utilizado no âmbito
do choque de gestão mineiro.
Entre as relações contratuais
de governança que a reforma
busca implementar, os termos
de parceria chamam particular
atenção pelo resgate da
estratégia de publicização na
delegação da provisão de
serviços públicos à sociedade
civil organizada e pela ênfase
na gestão por resultados. O
modelo híbrido das Oscips
resgata as vantagens
gerenciais das organizações
sociais, ao passo que mantém
a qualificação e fomento

${ }^{12}$ PECI, Alketa et al. Oscips e termos de parceria com a sociedade civil - ob. cit., 2008, p. $1137-1162$ 
conforme as características das Oscips federais. ${ }^{13}$

\section{CONCLUSÃO}

Demonstrou-se neste artigo que embora o terceiro setor seja reconhecido como existente desde a colonização do Brasil, e sua evolução e reconhecimento a partir da década de 30 , ainda não são suficientes para sua plena finalidade.

Certamente a literatura demonstra que posteriormente ao Governo FHC houve um avanço no reconhecimento e separação das instituições que compõem o terceiro setor, principalmente no que condiz ao reconhecimento e regulamentação das OSCIP's as quais passaram a ter leis que facilitem suas arrecadações.

Neste momento, reconhece-se as OSCIPs como importante parceiro dentro da administração pública. Porém, ainda há que ser avaliado e melhorado as burocracias fiscais que envolvem e acabam por muitas vezes a dificultar a efetividade nas ações provindas dessa parceria.

\section{REFERÊNCIAS}

ASSUMPCAO, Jairo José; CAMPOS, Lucila Maria de Souza. Avaliação de projetos sociais em ONGs da Grande Florianópolis: um estudo sobre modelos relacionados ao foco de atuação. Rev. Adm. Pública [online], 2011, v. 45, n. 1, p. 209 - 242.

CARRION, Rosinha Machado. Organizações privadas sem fins lucrativos: a participação do mercado no terceiro setor. Tempo soc. [online], 2000, v. 12, n. 2, p. 237 - 255.

LOPES, José Rogério. Terceiro setor: a organização das políticas sociais e a nova esfera pública. Perspec. [online], 2004, v. 18, n. 3, p. $57-66$.

MADEIRA, Felícia Reicher; BIANCARDI, Miriam Ribeiro. O desafio das estatísticas do

\footnotetext{
${ }^{13}$ PECI, Alketa et al. Oscips e termos de parceria com
} a sociedade civil - ob. cit., 2008, p. 1137 - 1162.
Terceiro Setor. Perspec. [online], 2003, v. 17, n. 3 - 4, p. 177 - 184.

MENEZES, Franciane Cristina de. O Serviço Social e a "responsabilidade social das empresas": o debate da categoria profissional na Revista Serviço Social \& Sociedade e nos CBAS. Serv. Soc. Soc. [online], 2010, n. 103, p. $503-531$.

PECI, Alketa et al. Oscips e termos de parceria com a sociedade civil: um olhar sobre o modelo de gestão por resultados do governo de Minas Gerais. Rev. Adm.

Pública [online], 2008, v. 42, n. 6, p. 1137 1162.

SILVA, Carlos Eduardo Guerra. Gestão, legislação e fontes de recursos no terceiro setor brasileiro: uma perspectiva histórica. Rev. Adm. Pública [online], 2010, v. 44, n. 6, p. $1301-1325$. 